\title{
Algebraic Observer Design for PEM Fuel Cell System
}

\author{
Zakaria BAROUD, Noureddine GAZZAM, Atallah BENALIA \\ Electrical Engineering Department, \\ LACoSERE Laboratory \\ Amar Telidji University, \\ Laghouat, Algeria. \\ E-mail: [z.baroud, n.gazzam a.benalia]@lagh-univ.dz
}

\author{
Carlos OCAMPO-MARTINEZ \\ Automatic Control Department \\ Institut de Robòtica \\ i Informàtica Industrial (CSIC-UPC), \\ 08028 Barcelona, Spain. \\ E-mail: cocampo@iri.upc.edu
}

\begin{abstract}
In this paper, the concept of the algebraic observer is applied to Proton Exchange Membrane Fuel Cell (PEMFC) system. The aim of the proposed observer is to reconstruct the oxygen excess ratio through estimation of their relevant states in real time from the measurement of the supply manifold air pressure. A robust differentiation method is adopted to estimate in finite-time the time derivative of the supply manifold air pressure. Then, the relevant states are reconstructed based on the output-state inversion model. The objective is to minimize the use of extra sensors in order to reduce the costs and enhance the system accuracy. The performance of the proposed observer is analyzed through simulations considering measurement noise and different stack-current variations. The results show that the algebraic observer estimates in finite time and robustly the oxygen-excess ratio.
\end{abstract}

Index Terms-PEM Fuel Cell system, oxygen excess ratio, algebraic observer, numerical differentiator.

\section{INTRODUCTION}

$\mathbf{T}$ he serious environmental pollution and energy crisis around the world are driving innovation on new efficient and clean energy sources such as solar, wind, geothermal and hydrogen. Fuel cells are a kind of clean energy, which produce electricity, water and heat from hydrogen and oxygen [1].

In particular, Proton Exchange Membrane fuel cells (PEMFC), also called solid polymer fuel cells (SPFCs), are considered to be more developed than other types of fuel cells [2]. They are used in a wide range of applications, with advantages such as high efficiency, low weight, low pollution and low operation temperature, features that allow fast starting times in the PEMFC systems [3]. However, high expenses and short lifetime have hindered their massive utilization in real systems so far. As a result, advanced control systems are required to improve the lifetime and avoid the detrimental degradation of the PEMFC system.

One of the major problem in the PEMFC system is "oxygen starvation" when the stack current increases rapidly, in order to avoid the oxygen starvation and extended the life of the PEMFC, many control strategies have been proposed to regulate fast and efficiently the oxygen depleted from the fuel cell cathode. It can be cited, among others, linear control methods based on model linearization such as Linear Quadratic Regulator (LQR), proportional integral (PI) plus static feed- forward controller are proposed in [4] and [5], Second Order Sliding Mode (SOSM) based on super-twisting algorithm is proposed in [6] and [7]. In [8], a hybrid controller based on fuzzy logic and conventional PID is designed. Nevertheless, all these control strategies require the knowledge of the precise value of oxygen excess ratio. Unfortunately, it depends on the internal variables which are the partial pressures of oxygen and nitrogen in the cathode channel and the air pressure in the supply manifold, this means they should be measured by using physical extra sensors that increase the cost, the complexity and low the accuracy of the PEMFC system. For these reasons, the observation of the "observable states" using only the measurement state became an attractive and economical solution.

Over the last decades, several studies have focused on the observer design for fuel cell systems. We mention here some available results, [9] proposed an approach to estimate the states of the PEMFC system using the Kalman filter (EKF), based on a linearized model. Kim designed a nonlinear state observer by using the derivatives of the pressures in the cathode and in the anode [10]. Rakhtala et al. presented a finite-time High-Order Sliding Mode (HOSM) observer to estimate some key states in the PEMFC system [11]. These methods are applied for the estimation of the oxygen excess ratio in the PEMFC with different degree of success.

In this paper, an algebraic observer is introduced to estimate state variables in the PEMFC system. The algebraic observer theory [12] [13] allows the reconstruction of the system state variables in terms of inputs, outputs and their time derivatives up to some finite number. Thus, the accuracy and the robustness of the differentiator method are the key elements of the observer design, a robust differentiation method based on the works of [14] and [15] is used to estimate the time derivatives of output and input variables in finite-time. The proposed observer estimates the partial pressures of oxygen and nitrogen from the measurements of the supply manifold air pressure.

The remainder of the paper is organized as follows. The mathematical model of the PEMFC air supply system is explained in Section II. In Section III, The designing of the algebraic observer is presented. The proposed algebraic 
observer is applied to the model of the PEMFC system and the simulation results for different stack current changes and for noise in measurements are presented in detail in Section IV. Finally, the major conclusions are resumed in Section V.

\section{Nonlinear PEMFC System Model}

The PEMFC system includes five main sub-processes: the air flow (breathing), the hydrogen flow, the humidifier, the stack electrochemistry and the stack temperature. According to [16], it is considered that sufficient compressed hydrogen is available. In addition, it is assumed that both temperature and humidity of input reactant flows are properly regulated by dedicated local controllers, and thus the main regard is focused on the air management. Under these assumptions, a fourth-order state-space model is derived, which is a reduced version of the ninth-order model presented in [9].

The vector of states $x \in \mathbb{R}^{4}$ is associated to the partial pressure of oxygen and nitrogen in the cathode channel, the rotational speed of the motor shaft in the compressor and the air pressure in the supply manifold, respectively. The control input $u \in \mathbb{R}$ is the compressor motor voltage $v_{c m}$, which allows the manipulation of the air feed and, as a consequence, the oxygen supply to the fuel-cell stack. The measurable disturbance input $w \in \mathbb{R}$ is the stack current $I_{s t}$.

The governing equations for the partial pressures of oxygen and nitrogen in the cathode, for the air pressure in the supply manifold and for the rotational speed of the motor shaft in the compressor are given as follows [17]:

$$
\begin{aligned}
\frac{d x_{1}}{d t} & =c_{1}\left(x_{4}-\chi\right)-\frac{c_{3} x_{1} \alpha\left(x_{1}, x_{2}\right)}{c_{4} x_{1}+c_{5} x_{2}+c_{6}}-c_{7} w \\
\frac{d x_{2}}{d t} & =c_{8}\left(x_{4}-\chi\right)-\frac{c_{3} x_{2} \alpha\left(x_{1}, x_{2}\right)}{c_{4} x_{1}+c_{5} x_{2}+c_{6}} \\
\frac{d x_{3}}{d t} & =-c_{9} x_{3}-\frac{c_{10}}{x_{3}}\left(\left(\frac{x_{4}}{c_{14}}\right)^{c_{12}}-1\right) h_{y 3}\left(x_{3}, x_{4}\right)+c_{13} u,
\end{aligned}
$$$$
\frac{d x_{4}}{d t}=\phi c_{14}\left(1+\left(c_{15}\left(\frac{x_{4}}{c_{11}}\right)^{c_{12}}-1\right)\right),
$$

with $\phi=\left(h_{y 3}\left(x_{3}, x_{4}\right)-c_{16}\left(x_{4}-\chi\right)\right)$, where the constants $c_{i}, i \in[1, \ldots, 24]$ are defined in Table I in the Appendix, the cathode pressure, $\chi$, is the sum of three partial pressures, $\left(x_{1}, x_{2}, c_{2}\right)$ and the cathode outlet mass flow rate, $\alpha\left(x_{1}, x_{2}\right)$, is expressed as follows:

$$
\alpha=c_{17} \chi\left(\frac{c_{11}}{\chi}\right)^{c_{18}} \sqrt{1-\left(\frac{c_{11}}{\chi}\right)^{c_{12}}}
$$

The system output $h_{y} \in \mathbb{R}^{3}$, as illustrated in Figure 1 , is the stack voltage $h_{y_{1}}=v_{s t}$, the supply manifold air pressure $h_{y_{2}}=x_{4}$ and the air flow rate through the compressor $h_{y_{3}}=$ $W_{c p}$, respectively. The last of these depends on the rotational speed of the motor shaft in the compressor and the air pressure

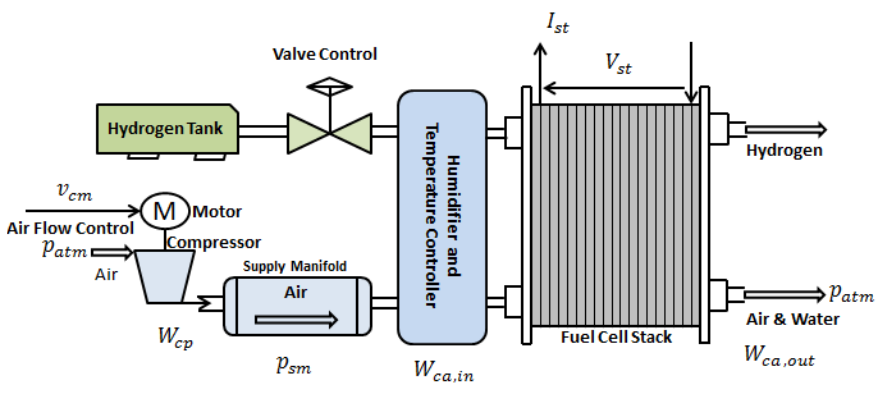

Figure 1: Fuel Cell System showing control inputs and outputs

in the supply manifold, that has been approximated with the following equation:

$$
h_{y_{3}}=\frac{h_{y_{3}}^{\max } x_{3}}{x_{3}^{\max }}\left(1-\exp \left(\frac{-r\left(s+\frac{x_{3}^{2}}{q}-x_{4}\right)}{s+\frac{x_{3}^{2}}{q}-x_{4}^{\min }}\right)\right),
$$

with $r=15, q=462.25 \mathrm{rad}^{2} /\left(\mathrm{s}^{2} \mathrm{~Pa}\right), x_{3}^{\max }=11500 \mathrm{rad} / \mathrm{s}$, $x_{4}^{\text {min }}=50000 \mathrm{~Pa}, s=100000 \mathrm{~Pa}$ and $h_{y_{3}}^{\max }=0.0975 \mathrm{Kg} / \mathrm{s}$. For further details on the functions $h_{y_{1}}$ and $h_{y 3}$, see [9], [17] and [18].

The performance variables $z \in \mathbb{R}^{2}$, with $z_{1}$ as net power and $z_{2}$ as oxygen excess ratio, are given as follows:

$$
\begin{aligned}
& z_{1}=h_{y 1}\left(x_{1}, x_{2}\right) w-c_{21} u\left(u-c_{22} x_{3}\right), \\
& z_{2}=\frac{c_{23}\left(x_{4}-\chi\right)}{c_{24} w} .
\end{aligned}
$$

In the next section, the algebraic observer based on a robust differentiation method will be designed in order to estimate the oxygen excess ratio in the PEMFC system from the measurements of the input and outputs for the control purposes.

\section{Algebraic ObSERVER DESIGN FOR PEMFC SySteM}

This section is devoted to the algebraic observer design for the control purpose in the PEMFC system, as depicted in Figure 2. However, before to design the observer, the observability of the PEMFC system should be verified, which can be investigated by checking the observability rank condition. This latter is achieved according to [19]. The proposed observer is known for its finite-time convergence and its robustness. In general, it is based on the robust differentiation of the outputs and inputs [15] and the output-state inversion.

At the stage of controller design, it is needed to estimate the sum of the oxygen and nitrogen partial pressures at the cathode channel (or the expression $x_{1}+x_{2}$ ). Estimation of this expression directly influences by (8) the calculation of oxygen excess ratio in the PEMFC system. The expression $\left(x_{1}+x_{2}\right)$ can be calculated using only the first derivative of the supply manifold air pressure $x_{4}$ in (4). In order to get robustly the first derivative of $x_{4}$, the algebraic observer detailed in [14] is used. Moreover, [20] provides the robust computation of the output derivative $x_{4}$ as follows:

$$
\hat{\dot{x}}_{4}=\int_{0}^{T} \frac{6}{T^{3}}(2 T-3 \tau) Y(t-\tau) d \tau,
$$




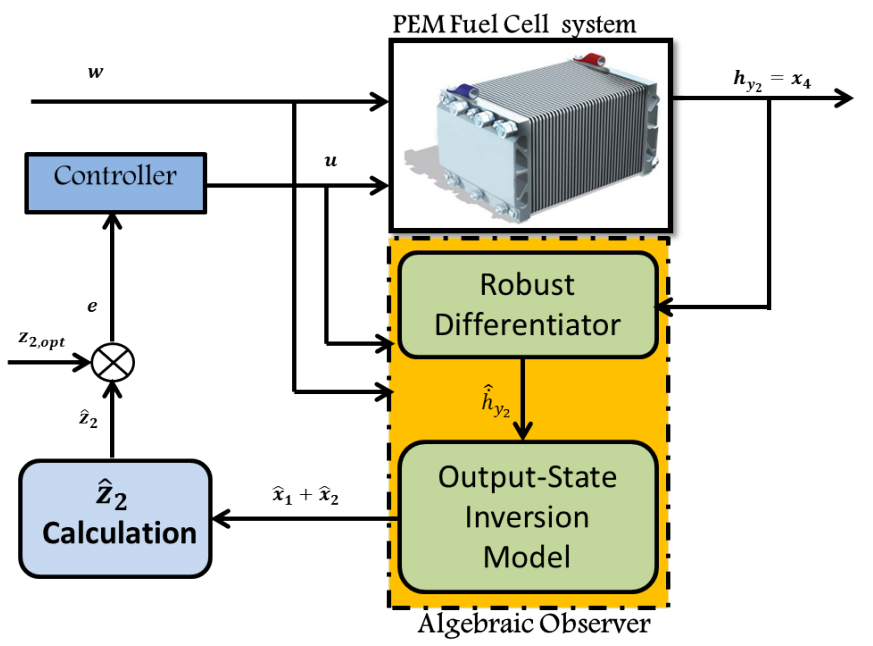

Figure 2: Algebraic observer-based output feedback control for PEMFC system

where $T$ is a positive constant, which is chosen to improve the precision of the estimated derivative and $Y$ represents the supply manifold pressure measurement. One can obtain robustly the expression $\hat{x}_{1}+\hat{x}_{2}$ from (4) and (9) as follows:

$$
\hat{x}_{1}+\hat{x}_{2}=\frac{1}{c_{16}}\left(\frac{\hat{\dot{x}}_{4}}{c_{14}\left(1+\left(c_{15}\left(\frac{x_{4}}{c_{11}}\right)^{c_{12}}-1\right)\right)}-h_{y 3}\right)
$$

Note that the convergence time of the proposed observer is $t_{c o n v}=T$, after this time the estimated relevant states, $\left(\hat{x}_{1}+\right.$ $\hat{x}_{2}$ ), reach the real states, $x_{1}+x_{2}$, i.e.,

$$
\hat{x}_{1}+\hat{x}_{2}=x_{1}+x_{2} .
$$

The proposed observer is schematically shown in Figure 2 , where $\hat{z}_{2}$ is estimated using the expression provided by the algebraic observer $\left(\hat{x}_{1}+\hat{x}_{2}\right)$ and the nominal PEMFC parameters, defined in Table I in the Appendix according to the following expression:

$$
\hat{z}_{2}=\frac{c_{23}\left(x_{4}-\left(\hat{x}_{1}+\hat{x}_{2}+c_{2}\right)\right)}{c_{24} w} .
$$

\section{Simulation Results and Analysis}

To show the efficiency and the robustness of the observer presented in Section III, detailed simulations are performed and analyzed. The numerical parameters used in the simulation are given in Table II in the Appendix. The initial states values are chosen as

$$
x(0)=\left[\begin{array}{llll}
11104 \mathrm{~Pa} & 83893 \mathrm{~Pa} & 5100 \mathrm{rad} / \mathrm{s} & 148000 \mathrm{~Pa}
\end{array}\right]^{T} .
$$

In the first place, the PEMFC system is supposed to be well controlled as shown in Figure 2, where the controller adopted in this study is taken directly from [6] to maintain the oxygen excess ratio at its optimal value $z_{2, \text { opt }}$.

\section{A. Performance Results}

The main purpose of the algebraic observer design is to reconstruct the oxygen excess ratio in order to be useful for control purposes. The estimation of oxygen excess ratio value $\hat{z}_{2}$ under different stack current variations (see Figure 3), using an algebraic observer strategy is shown in Figure 5. The stack current rises up from $100 \mathrm{~A}$ to $180 \mathrm{~A}$ at $t=7 \mathrm{~s}$. Next, after $7 \mathrm{~s}$, it increases by $70 \mathrm{~A}$. Then, the stack current increases again to reach $300 \mathrm{~A}$ at $t=20 \mathrm{~s}$. Finally, at time $t=25 \mathrm{~s}$, it decreases from $300 \mathrm{~A}$ to $250 \mathrm{~A}$ (Figure 3). It can be seen from Figure 5 that the algebraic observer is perfectly able to reconstruct the value of oxygen excess ratio in finite-time.

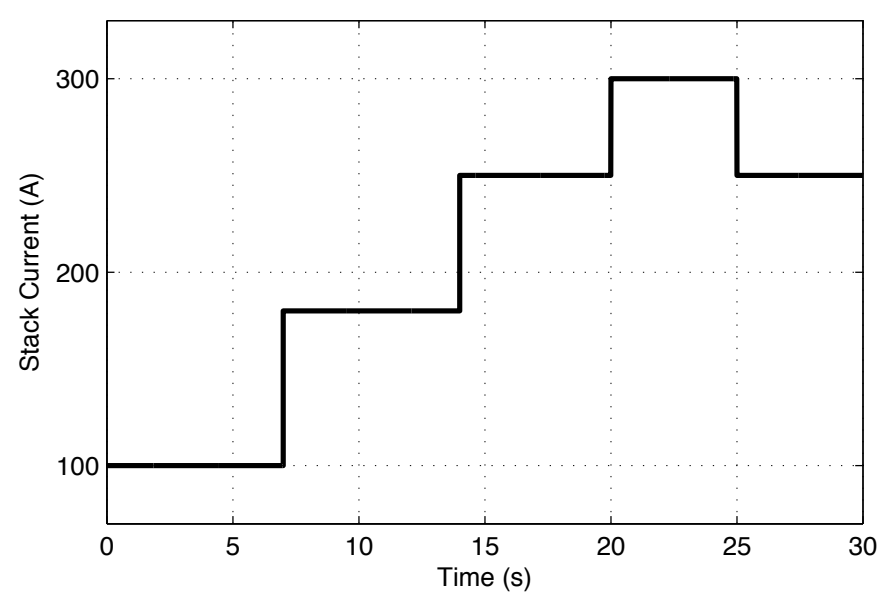

Figure 3: Stack current variation

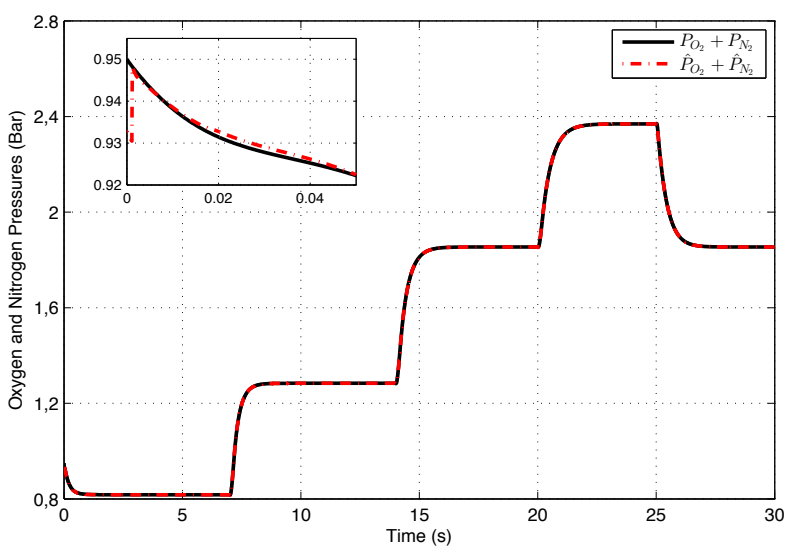

Figure 4: Estimation of the oxygen and nitrogen partial pressures

Figure 4 presents the partial pressures of oxygen and nitrogen and its estimations, which are well estimated based on the robust differentiation of the supply manifold air pressure. At the beginning of the estimation, the proposed observer reached the real values of $x_{1}+x_{2}$ in less than $30 \mathrm{~ms}$. The estimation error oxygen excess ratio is shown in Figure 6. In spite of having a stack current variations the estimation error is acceptably small. 


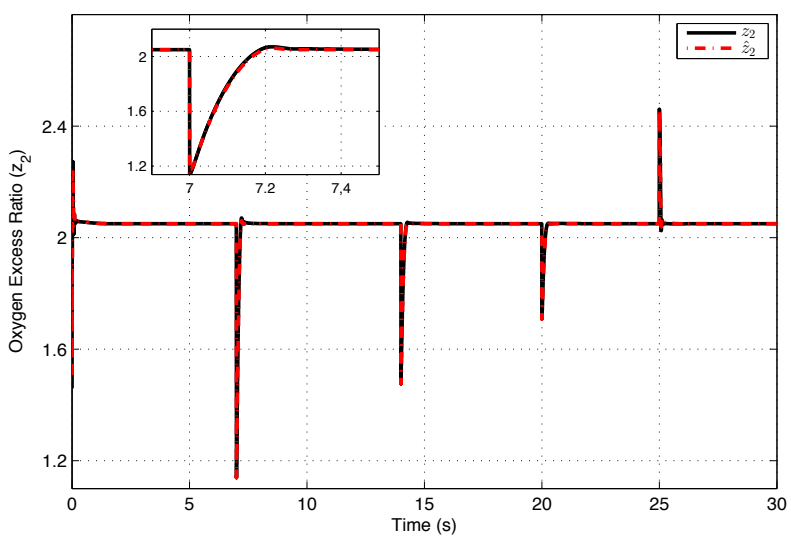

Figure 5: Oxygen excess ratio estimation

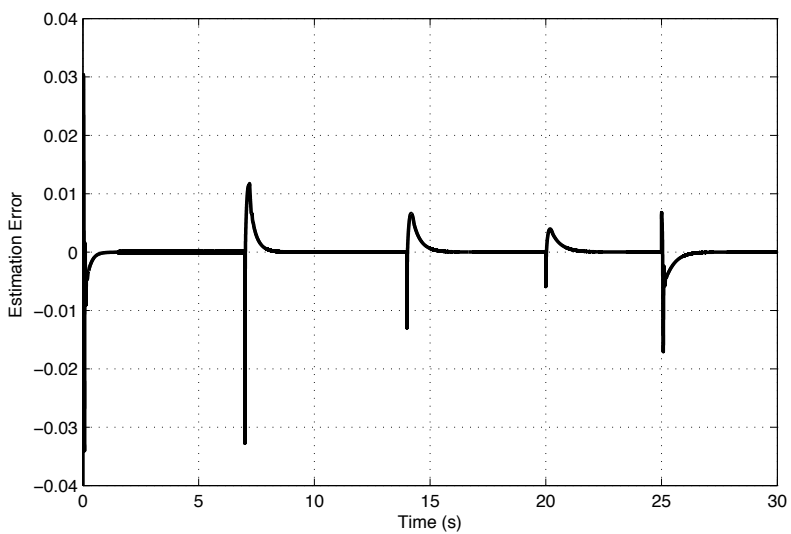

Figure 6: Error estimation $z_{2}-\hat{z}_{2}$

\section{B. Robustness test: Noise in the measurement}

In order to test the robustness of the proposed observer some simulations were carried out in the presence of measurement noise in the measurement $x_{4}$. Let $Y=x_{4}+\xi(t)$ be the real measurement of $x_{4}$ where $\xi(t)$ is a noisy signal.

The function $\xi(t)$ used in the simulations is presented in Figure 7. The simulation results are shown in Figures 8-10. The oxygen excess ratio estimation is depicted in Figure 9. In that figure, it is possible to see that the algebraic observer estimates the oxygen excess ratio well enough in spite of the noise in the measurement.

\section{CONCLUSION}

In this paper, a reduced PEMFC system model is proposed, which presents cathode mass flow transients. Based on this model, an algebraic observer is designed to estimate the oxygen excess ratio. The proposed observer used a robust differentiation method to estimate the derivative of the supply manifold air pressure in finite-time. then, the oxygen and the nitrogen partial pressures were successfully estimated from the derivative estimated of the supply manifold air pressure. Simulation results show the robustness and the feasibility of the proposed observer. As future research, the applicability of

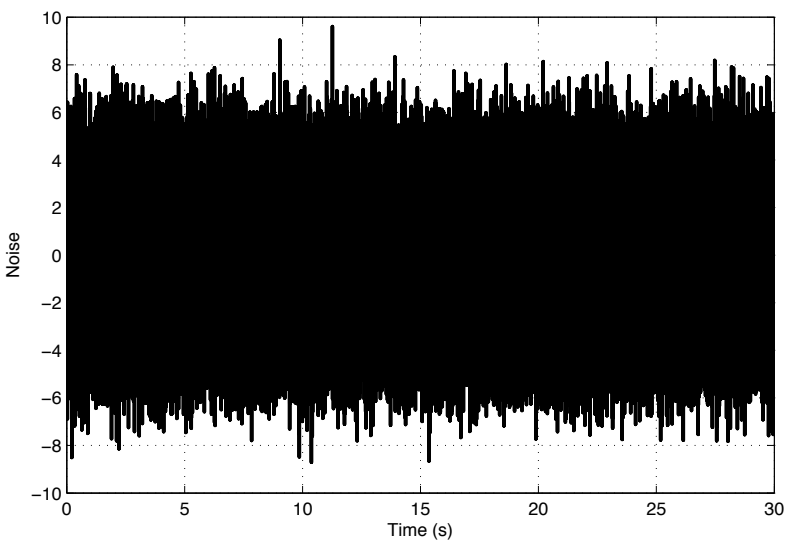

Figure 7: Noise $\xi$ affecting the system output $x_{4}$

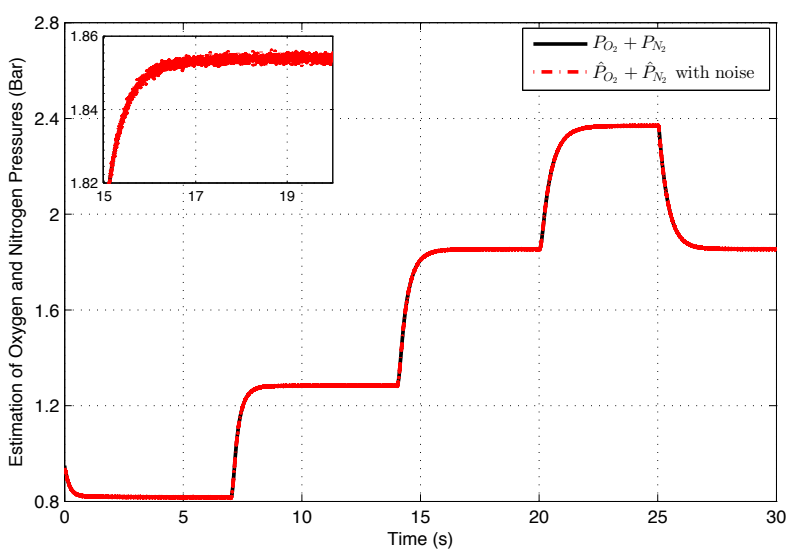

Figure 8: Estimation of the oxygen and nitrogen partial pressures with noise in $x_{4}$

the algebraic observer will be confirmed in an experimental test bench.

\section{REFERENCES}

[1] N. Yousfi-Steiner, P. Moçotéguy, D. Candusso, D. Hissel (2009) 'A review on polymer electrolyte membrane fuel cell catalyst degradation and starvation issues: Causes, consequences and diagnostic for mitigation', Journal of Power Sources 194 (1) (2009) 130 - 145.

[2] J. Larminie, A. Dicks, M. S. McDonald (2003) 'Fuel cell systems explained', Vol. 2, Wiley New York, 2003.

[3] W. Vielstich, A. Lamm, H.A. Gasteiger (2009) 'Handbook of fuel cells: fundamentals, technology, and applications', Vol. 2 , John Wiley \& Sons, 2009.

[4] J.T.Pukrushpan, A. Stefanopoulou, H. Peng (2004) 'Control of fuel cell breathing', IEEE, Control Systems, 24 (2) (2004) 30-46.

[5] A. Niknezhadi, M. Allué-Fantova, C. Kunusch, C. Ocampo-Martìnez (2011) 'Design and implementation of LQR/LQG strategies for oxygen stoichiometry control in PEM fuel cells based systems', Journal of Power Sources, 196 (9) (2011) 4277 - 4282.

[6] C. Kunusch, P. Puleston, M. Mayosky, J. Riera (2009) 'Sliding mode strategy for PEM fuel cells stacks breathing control using a super-twisting algorithm', IEEE Transactions on, Control Systems Technology, 17 (1) (2009) 167-174.

[7] Z. Baroud, M. Benmiloud, A. Benalia (2015) 'Sliding mode controller for breathing subsystem on a PEM fuel cell system', in: 3rd International Conference on, Control and Engineering Information Technology (CEIT), 2015, pp. 1-6. 


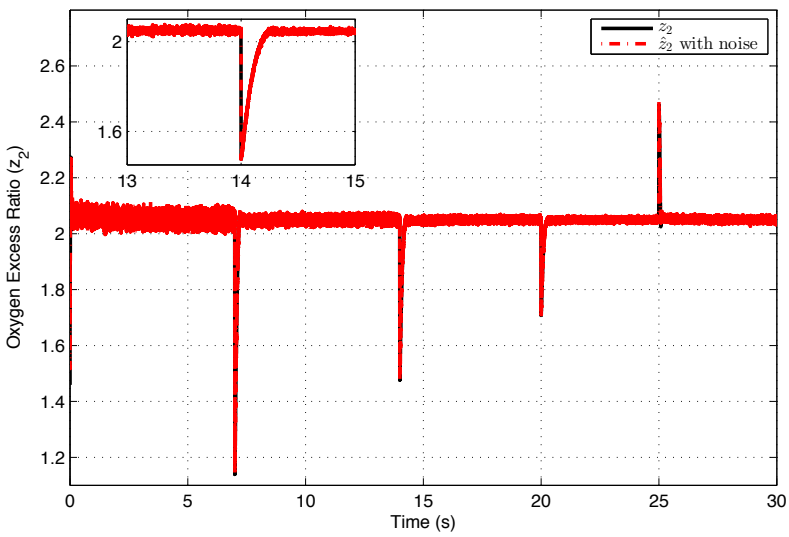

Figure 9: Oxygen excess ratio estimation with noise in $x_{4}$

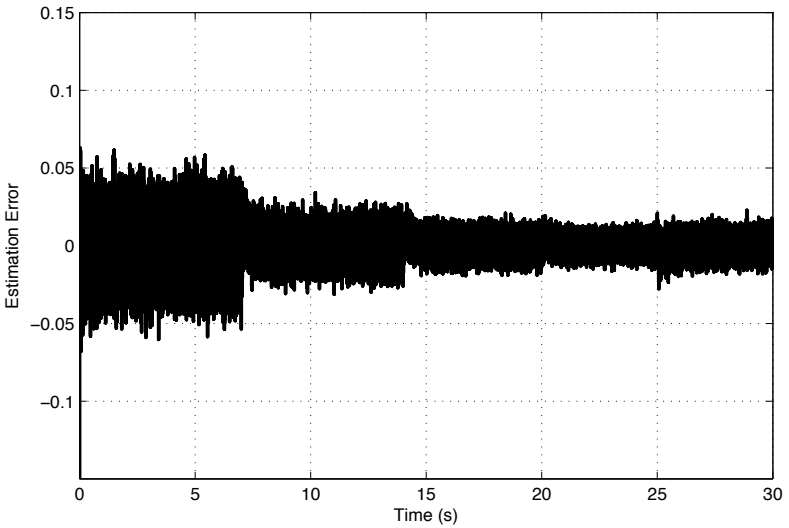

Figure 10: Error estimation with noise in $x_{4}$

[8] Z. Baroud, M. Benmiloud, A. Benalia (2015) 'Fuzzy self-tuning PID controller for air supply on a PEM fuel cell system', in: 4th International Conference on Electrical Engineering (ICEE), 2015, pp. 1-4.

[9] J. Pukrushpan, A. Stefanopoulou, H. Peng (2004) 'Fuel Cell System Model: Fuel Cell Stack', in: Control of Fuel Cell Power Systems, Springer London, 2004.

[10] E. Kim (2012) 'Observer Based Nonlinear State Feedback Control of PEM Fuel Cell Systems', Journal of Electrical Engineering \& Technology 7 (6) (2012) $891-897$.

[11] S.M. Rakhtala, A.R. Noei, R. Ghaderi, E. Usai (2014) 'Design of finitetime high-order sliding mode state observer: A practical insight to PEM fuel cell system', Journal of Process Control 24 (1) (2014) 203 - 224.

[12] M. Fliess, M. Hazewinkel (1986) 'Algebraic and Geometric Methods in Nonlinear Control Theory'. Dordrecht: Springer Netherlands (1986). Internet resource.

[13] J. Liu, S. Laghrouche, Z.S. Ahmed, M. Wack (2015) 'PEM fuel cell air-feed system observer design for automotive applications: An adaptive numerical differentiation approach', International Journal of Hydrogen Energy 39 (30) (2014) 17210 - 17221.

[14] M. Fliess, H.J. Sira-Ramirez (2003) 'State reconstructors: a possible alternative to asymptotic observers and Kalman filters', Proceedings of CESA, (2003).

[15] M. Fliess, H. J. Sira-Ramirez (2004) 'Control via state estimations of some nonlinear systems', IFAC Symposium on Nonlinear Control Systems (NOLCOS), Stuttgart, (2004).

[16] K. W. Suh (2006) 'Modeling, analysis and control of fuel cell hybrid power systems', Ph.D. thesis (2006).

[17] J. Gruber, C. Bordons, F. Dorado (2008) 'Nonlinear control of the air feed of a fuel cell', in: American Control Conference, 2008, pp. 11211126.

[18] Z. Baroud, M. Benmiloud, A. Benalia (2014) 'Modelling and Analysis of Proton Exchange Membrane Fuel Cell System', in: 3rd International Con- ference on, Information Processing and Electrical Engineering (ICIPEE), 2014, pp. 1-6.

[19] J. Liu, S. Laghrouche, M. Wack (2013) 'Differential flatness-based observer design for a PEM fuel cell using adaptive-gain sliding mode differentiators', Control Conference (ECC) (2013), European, Zurich, 2477-2482.

[20] M. Mboup, C. Join, M. Fliess (2007) 'A revised look at numerical differentiation with an application to nonlinear feedback control', 15th Mediterrean Conference on Control and Automation-MED, (2007).

\section{APPENDIX}

Table I: Constants of the PEMFC system model

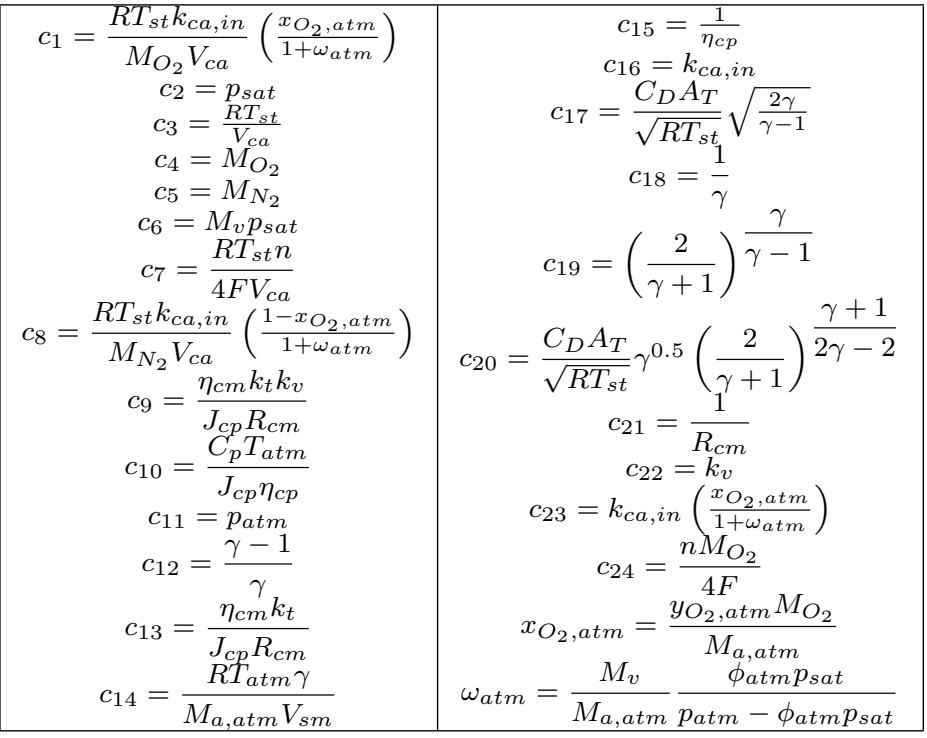

Table II: Simulation Parameters

\begin{tabular}{|c|c|c|c|}
\hline Parameter & Description & Value & Unit \\
\hline$\eta_{c p}$ & Motor mechanical efficiency & 0.98 & $\%$ \\
\hline$\eta_{c m}$ & Compressor efficiency & 0.8 & $\%$ \\
\hline$J_{c p}$ & Compressor inertia & $5 \times 10^{-5}$ & $\mathrm{~kg} \mathrm{~m}^{2}$ \\
\hline$R_{c m}$ & Compressor motor resistance & 0.82 & $\Omega$ \\
\hline$k_{t}$ & Motor parameter & 0.0153 & $(\mathrm{~N} \mathrm{~m}) / \mathrm{A}$ \\
\hline$k_{v}$ & Motor parameter & 0.0153 & $\mathrm{~V} /(\mathrm{rad} / \mathrm{s})$ \\
\hline$M_{a, a t m}$ & Air molar mass & $29 \times 10^{-3}$ & $\mathrm{~kg} \mathrm{~mol}^{-1}$ \\
\hline$M_{O_{2}}$ & Oxygen molar mass & $32 \times 10^{-3}$ & $\mathrm{~kg} \mathrm{~mol}^{-1}$ \\
\hline$M_{N_{2}}$ & Nitrogen molar mass & $28 \times 10^{-3}$ & $\mathrm{~kg} \mathrm{~mol}^{-1}$ \\
\hline$M_{v}$ & Vapor molar mass & $18 \times 10^{-3}$ & $\mathrm{~kg} \mathrm{~mol}{ }^{-1}$ \\
\hline$y_{O_{2}, a t m}$ & Oxygen mole fraction & 0.21 & - \\
\hline$V_{c a}$ & Cathode volume & 0.01 & $\mathrm{~m}$ \\
\hline$k_{c a, i n}$ & Cathode inlet orifice constant & $0.3629 \times 10^{-5}$ & $\mathrm{~kg} /(\mathrm{s} \mathrm{Pa})$ \\
\hline$V_{s m}$ & Supply manifold volume & 0.02 & $\mathrm{~m}{ }^{3}$ \\
\hline$T_{s t}$ & Stack temperature & 353.15 & $\mathrm{~K}$ \\
\hline$T_{a t m}$ & Atmospheric temperature & 298.15 & $\mathrm{~K}$ \\
\hline$p_{a t m}$ & Atmospheric pressure & 101325 & $\mathrm{~Pa}$ \\
\hline$p_{s a t}$ & Saturation pressure & 465327.41 & $\mathrm{~Pa}$ \\
\hline$R$ & Universal gas constant & 8.3145 & $\mathrm{~J} /(\mathrm{mol} \mathrm{K})$ \\
\hline$C_{p}$ & Constant pressure Specific heat of air & 1004 & $\mathrm{~J} /(\mathrm{mol} \mathrm{K})$ \\
\hline$C_{D}$ & Cathode outlet throttle discharge coefficient & 0.0124 & - \\
\hline$\gamma$ & Ratio of specific heat of air & 1.4 & - \\
\hline$A_{T}$ & Cathode outlet throttle area & 0.002 & $\mathrm{~m}{ }^{2}$ \\
\hline$\phi_{a t m}$ & Average ambient air relative humidity & 0.5 & - \\
\hline$n$ & Number of cells in fuel-cell stack & 381 & - \\
\hline$F$ & Faraday number & 96485 & $\mathrm{Cmol}{ }^{-1}$ \\
\hline & & & \\
\hline & & & \\
\hline & & & \\
\hline
\end{tabular}

